\title{
Enhanced cytotoxicity of bleomycin and cisplatin after electroporation in murine colorectal carcinoma cells
}

\author{
Vesna Todorovic ${ }^{1}$, Gregor Sersa ${ }^{1}$, Karel Flisar ${ }^{3}$, Maja Cemazar ${ }^{1,2}$ \\ ${ }^{1}$ University of Primorska, College of Health Care Izola, Izola, ${ }^{2}$ Institute of Oncology Ljubljana, \\ Ljubljana, ${ }^{3}$ University of Ljubljana, Faculty of Electrical Engineering, Ljubljana, Slovenia
}

\begin{abstract}
Background. Electrochemotherapy is a local treatment combining application of electric pulses and chemotherapy. Two chemotherapeutic drugs, bleomycin and cisplatin, have proved to be effective in electrochemotherapy. The effectiveness of electrochemotherapy was demonstrated in the treatment of various cutaneous and subcutaneous tumours in cancer patients. Only a few preclinical studies were performed in colorectal carcinoma, mostly using bleomycin. Our aim was to evaluate the sensitivity of the murine colorectal carcinoma cell line CMT-93 to electrochemotherapy with bleomycin and cisplatin for potential use in preclinical and clinical studies.
\end{abstract}

Methods. CMT-93 cells were exposed to either the chemotherapeutic drug alone or electrochemotherapy. A clonogenic assay was used to determine cell survival after treatment. Apoptosis was measured by caspase-3/7 activity, necrosis by changes in cell morphology and cell viability by the MTS assay 16 hours after electrochemotherapy.

Results. Cells treated with electrochemotherapy were 500-fold more sensitive to bleomycin and 2.8-fold more sensitive to cisplatin compared to cells treated with the drugs alone. At the highest concentrations, a significant reduction in cell viability, increase in caspase-3/7 activity and necrotic cells were observed after electrochemotherapy.

Conclusions. Exposure of cells to electric pulses enhanced cytotoxicity of both bleomycin and cisplatin. Reduced cell viability was due to apoptotic and necrotic cell death. Furthermore, electrochemotherapy with bleomycin was more cytotoxic than electrochemotherapy with cisplatin in this colorectal carcinoma cell line.

Key words. electroporation; electrochemotherapy; colorectal carcinoma; bleomycin; cisplatin

Received 16 October 2009

Accepted 28 October 2009

Correspondence to: Prof. Maja Cemazar, PhD, Institute of Oncology Ljubljana, Zaloska cesta 2, SI1000 Ljubljana, Slovenia. Phone +386 158795 44; E-mail: mcemazar@onko-i.si

\section{Introduction}

Electroporation is the application of electric pulses to cells in vitro or tumours in vivo. It is effective in facilitating the transport of different molecules with otherwise hampered transport across the plasma 
membrane, including chemotherapeutic drugs. ${ }^{1,2}$ Electroporation can be used in combination with chemotherapy (electrochemotherapy) or gene therapy (electrogene therapy) to increase the uptake of chemotherapeutic drugs, or nucleic acids, respectively. So far, two chemotherapeutic drugs have proved to be effective in electrochemotherapy, bleomycin (BLM) and cisplatin (CDDP). Electroporation with BLM or CDDP significantly enhances the cytotoxicity of these drugs in different tumour cell lines, also of CDDP-resistant cell lines and solid experimental tumours. ${ }^{3-6}$ Furthermore, its effectiveness was demonstrated in the treatment of various cutaneous and subcutaneous tumours of various malignancies..$^{7,8}$

Colorectal carcinoma is one of the most common cancers worldwide, and its incidence is increasing. Traditional treatment modalities for colorectal carcinoma are surgery, chemotherapy and/or radiation. However, not all patients can undergo surgery due to severe complications, such as chronic heart failure, chronic renal failure, and chronic obstructive pulmonary diseases. ${ }^{9}$ Chemotherapy can be used for these patients, yet its effectiveness is limited by side effects. However, if further progress in reducing colorectal carcinoma mortality is to be accomplished, new treatment strategies are needed.

Electrochemotherapy could provide an innovative therapeutic approach for the treatment of colorectal carcinoma. The majority of studies evaluating the antitumour effect of electrochemotherapy concentrated on cutaneous and subcutaneous tumours of various histology, and only a few on colorectal carcinoma. ${ }^{9,10}$ Therefore, the aim of our study was to evaluate the in vitro sensitivity of the murine colorectal carcinoma cell line CMT-93 to electrochemotherapy with BLM and CDDP for potential use in preclinical and clinical studies on colorectal carcinoma.

\section{Materials and methods}

\section{Cell line}

Murine rectum carcinoma cells CMT-93 (American Type Culture Collection, USA) were grown in Dulbecco's Modified Eagle Medium (DMEM) with Glutamax (Gibco, Invitrogen, Paisley, UK), supplemented with $10 \%$ foetal calf serum (FCS) (Invitrogen, Paisley, UK) and gentamicin $(30 \mu \mathrm{g} / \mathrm{mL})$ (Gibco, Invitrogen, Paisley, UK). Cells were routinely subcultured twice a week and incubated in an atmosphere with $5 \% \mathrm{CO}_{2}$ at $37^{\circ} \mathrm{C}$.

\section{Drugs}

BLM (Blenamax) was obtained from Pharmachemie BV (Haarlem, the Netherlands) as a crystalline powder. BLM was dissolved in saline $(0.9 \% \mathrm{NaCl})$ at a concentration 1.5 $\mathrm{mg} / \mathrm{mL}$. CDDP (Cisplatyl) was obtained from Aventis (Paris, France) as a crystalline powder. CDDP was dissolved in sterile $\mathrm{H}_{2} \mathrm{O}$ at a concentration of $1 \mathrm{mg} / \mathrm{mL}(3.3 \mathrm{mM})$. For each experiment, a fresh solution of BLM or CDDP was prepared. The final concentrations of both BLM and CDDP were prepared in DMEM. BLM concentrations of 0.00001 $\mu \mathrm{M}$ to $1 \mu \mathrm{M}$ and CDDP concentrations of $6.7 \mu \mathrm{M}$ to $266.6 \mu \mathrm{M}$ were used in the experiments.

\section{Electrochemotherapy protocol}

Confluent cell cultures were trypsinized, washed in DMEM with FCS for trypsin inactivation and once in electroporation buffer (125 mM saccharose; $10 \mathrm{mM} \mathrm{K}_{2} \mathrm{HPO}_{4} ; 2.5$ $\left.\mathrm{mM} \mathrm{KH} \mathrm{PO}_{4} ; 2 \mathrm{mM} \mathrm{MgCl} 2 \cdot 6 \mathrm{H}_{2} 0\right)$ at $4{ }^{\circ} \mathrm{C}$. The final cell suspension was prepared in electroporation buffer at $4^{\circ} \mathrm{C}$ and a concentration of $22 \times 10^{6}$ cells $/ \mathrm{mL}$. For the clonogenic assay, $90 \mu \mathrm{L}$ of final cell suspension was mixed with $10 \mu \mathrm{L}$ of BLM or CDDP solution at different concentrations. $50 \mu \mathrm{L}$ 
of the mixture $\left(1 \times 10^{6}\right.$ cells $)$ were placed between two parallel electrodes with a 2 $\mathrm{mm}$ gap in-between and subjected to eight square wave electric pulses with electric field intensity $1300 \mathrm{~V} / \mathrm{cm}$, pulse duration $100 \mu$ s and frequency $1 \mathrm{~Hz}$. Electric pulses were generated by an in-house build electroporator (University of Ljubljana, Faculty of Electrical Engineering, Ljubljana, Slovenia). Another $50 \mu \mathrm{L}$ of the mixture $\left(1 \times 10^{6}\right.$ cells $)$ served as a control of CDDP treatment alone. After electroporation, cells were incubated at room temperature for $5 \mathrm{~min}$, diluted in $2 \mathrm{~mL}$ of growth medium and then plated for clonogenic, caspase-3/7 activity, cell viability assays, and Giemsa staining.

\section{Clonogenic assay}

CMT-93 cells were plated at a concentration of 300 cells/dish for exposure to BLM alone and 1200 cells/dish for combination of electroporation and BLM, whereas 600 cells/dish were plated for both CDDP alone and a combination of electroporation and CDDP. After 9 and 10 days (BLM and CDDP, respectively) colonies were fixed, stained with crystal violet and counted. The survival curve for the electrochemotherapytreated cells was normalised for the cytotoxicity of electric pulses treatment alone. The inhibitory concentration of each treatment that reduced cell survival to $50 \%\left(\mathrm{IC}_{50}\right)$ was determined graphically in each experiment. The experiment was repeated three times in triplicates for both BLM and CDDP.

\section{Apoptosis}

Apoptosis was measured by caspase- $3 / 7$ activity that was evaluated using the CaspaseGlo 3/7 Assay (Promega, Madison, USA) according to the manufacturer's instructions. After the electrochemotherapy protocol, CMT-93 cells $\left(1.5 \times 10^{4}\right.$ cells/well) were seeded in a 96-well plate (TPP, Trasadingen,
Switzerland) and incubated at $37^{\circ} \mathrm{C}$. After $16 \mathrm{~h}$, a solution of Caspase-Glo 3/7 substrate and buffer (ratio $20: 1$ ) (Promega, Madison, USA) was added to each well. Plates were further incubated at $37^{\circ} \mathrm{C}$ for $2 \mathrm{~h}$ and luminescence was measured at $1 \mathrm{~s}$ integration time using a microplate reader (Tecan, Salzburg, Austria). The experiment was repeated twice in quintuplicates. Caspase-3/7 activity was normalized to the number of viable cells (as determined by the cell viability assay). Caspase-3/7 fold induction was determined as the ratio between caspase-3/7 activity in treated and control cells.

Cell viability was evaluated using the CellTiter 96 Aqueous One Solution Cell Proliferation Assay (Promega, Madison, USA) according to the manufacturer's instructions. After the electrochemotherapy protocol, CMT-93 cells $\left(1.5 \times 10^{4}\right.$ cells/ well) were seeded in a 96-well plate (TPP, Trasadingen, Switzerland) and incubated at $37^{\circ} \mathrm{C}$. After $16 \mathrm{~h}$, a solution of MTS with PMS (ratio $20: 1$ ) was added to each well. Plates were further incubated at $37^{\circ} \mathrm{C}$ for $2 \mathrm{~h}$ and absorbance was measured at $492 \mathrm{~nm}$ using a microplate reader (Tecan, Salzburg, Austria). The experiment was repeated three times in quintuplicates.

\section{Necrosis}

Necrosis was evaluated by morphological changes in cells stained with Giemsa. For Giemsa staining, CMT-93 cells (7 x $10^{4}$ cells/ well) were plated in chamber slides $5 \mathrm{~min}$ after electroporation. After $18 \mathrm{~h}$, the medium was removed and cells were washed with PBS. Cells were fixed in cold methanol for $20 \mathrm{~min}$ and then washed under running water. Extra liquid was wiped away and Giemsa's azure eosin methylene blue solution (Merck, Darmstadt, Germany) was added to the slides for $20 \mathrm{~min}$. After incubation, slides were washed under running 

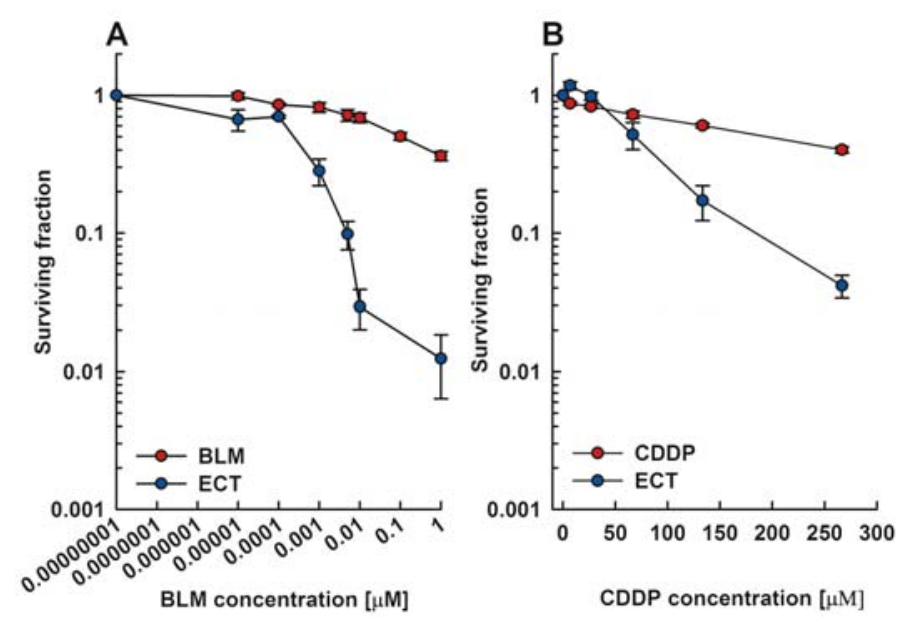

Figure 1. Potentiation of BLM and CDDP cytotoxicity in vitro by electroporation of CMT-93 cells. (A) Surviving fraction of CMT-93 cells after treatment with BLM alone or after electrochemotherapy with BLM. (B) Surviving fraction of CMT-93 cells after treatment with CDDP alone or after electrochemotherapy with CDDP.

water and air-dried. Samples were evaluated under a IX51 inverted microscope (Olympus, Tokyo, Japan). Photographs were taken with a CCD camera ColorView III (Soft Imaging System, Münster, Germany).

\section{Results}

\section{Clonogenic assay}

Exposure of CMT-93 cells to electric pulses resulted in an increase in both BLM and CDDP cytotoxicity (Figure 1). Throughout the range of BLM and CDDP concentrations investigated, cells exposed to either BLM or CDDP and electric pulses were more sensitive to the chemotherapeutics than those which were not exposed. The cells exposed to electric pulses were 2.8-fold more sensitive to CDDP as determined by the $\mathrm{IC}_{50}$ value. The cells exposed to electric pulses were 500-fold more sensitive to BLM as determined by the $\mathrm{IC}_{50}$ value. The surviving fraction of cells treated with electric pulses alone was $0.44 \pm 0.04$ (data not shown).
Apoptosis after electrochemotherapy with BLM

After BLM treatment, caspase- $3 / 7$ fold induction was significantly increased at $1 \mu \mathrm{M}$ BLM in comparison to other tested concentrations $(p<0.05)$. After electrochemotherapy with BLM, the caspase-3/7 fold induction was significantly increased both at $0.1 \mu \mathrm{M}$ and $1 \mu \mathrm{M}$ BLM. Interestingly, caspase-3/7 fold induction was higher at $0.1 \mu \mathrm{M}$ BLM; however, the difference was not significant (Figure 2).

The cell viability in the range of tested BLM concentrations was decreased and it reached $73 \%$ at the highest tested BLM concentration. In comparison to control non-treated cells, cell viability is significantly reduced at $0.0001 \mu \mathrm{M}$ BLM and higher $(\mathrm{p}<0.05)$. After electrochemotherapy with BLM, there was no significant difference in cell viability at low BLM concentrations $(0.00001 \mu \mathrm{M}-0.01$ $\mu \mathrm{M})$. However, at $0.1 \mu \mathrm{M}$ and $1 \mu \mathrm{M}$ BLM, cell viability was significantly reduced in comparison to other tested concentrations. Interestingly, there was no significant difference in cell viability between these two concentrations (Figure 2).

\section{Apoptosis after electrochemotherapy with CDDP}

After CDDP treatment, the caspase-3/7 fold induction was significantly increased at 266.6 $\mu \mathrm{M}$ CDDP in comparison to other tested concentrations $(\mathrm{p}<0.05)$. After electrochemotherapy with CDDP, the caspase-3/7 fold induction was significantly increased at $133.3 \mu \mathrm{M}$ and $266.6 \mu \mathrm{M}$ CDDP $(\mathrm{p}<0.05)$. Caspase-3/7 fold induction was 

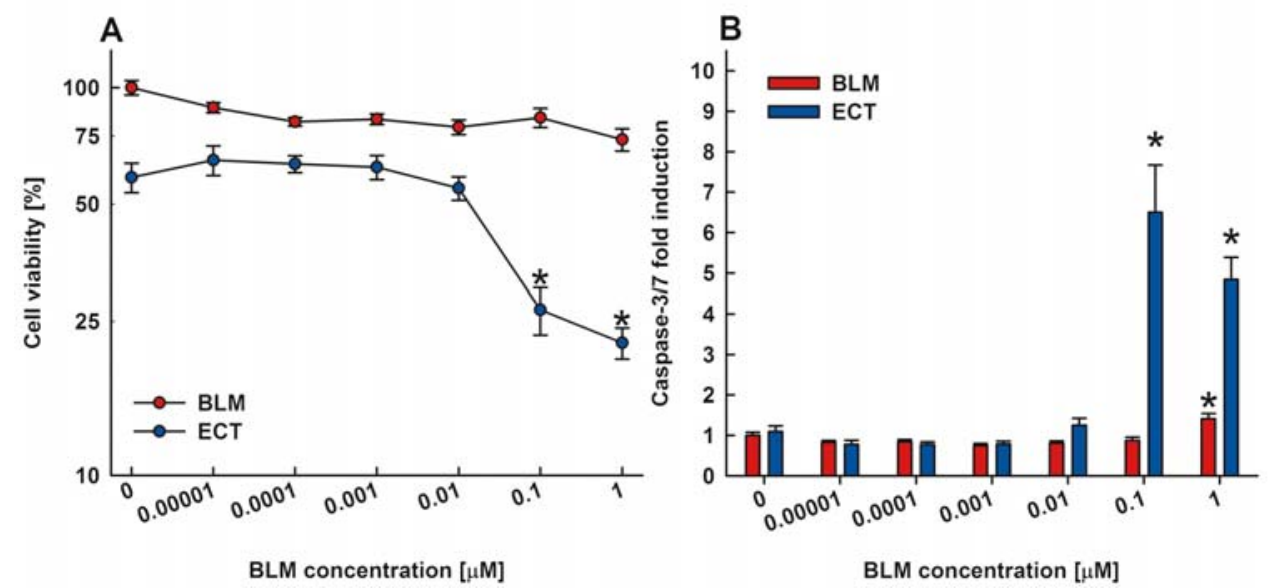

Figure 2. Cell viability (A) and caspase-3/7 fold induction (B) of CMT-93 cells after electrochemotherapy with BLM. Data are mean values pooled from two or three independent experiments. ${ }^{*} \mathrm{p}<0.05$.

significantly higher at $266.6 \mu \mathrm{M}$ than 133.3 $\mu \mathrm{M}$ CDDP $(\mathrm{p}<0.05)$ (Figure 3).

The cell viability in the range of tested CDDP concentrations was decreased and it reached $79 \%$ at the highest tested CDDP concentration. In comparison to control non-treated cells, cell viability after CDDP treatment was significantly reduced only at 133.3 $\mu \mathrm{M}$ and 266.6 $\mu \mathrm{M}$ CDDP $(\mathrm{p}<0.05)$. Interestingly, a significantly decreased cell viability was observed at 266.6 $\mu \mathrm{M}$ CDDP in comparison to other tested concentrations $(\mathrm{p}<0.05)$, but not to $133.3 \mu \mathrm{M}$. After electrochemotherapy with CDDP, cell viability was significantly reduced at 266.6 $\mu \mathrm{M}$ in comparison to all other tested concentrations $(\mathrm{p}<0.05)$ (Figure 3$)$.

\section{Necrosis after electrochemotherapy with $B L M$ or $C D D P$}

Cells were stained with Giemsa to evaluate the effect of BLM or CDDP treatment or electrochemotherapy with BLM or CDDP on cell morphology, specifically to determine necrosis. CMT-93 cells displayed
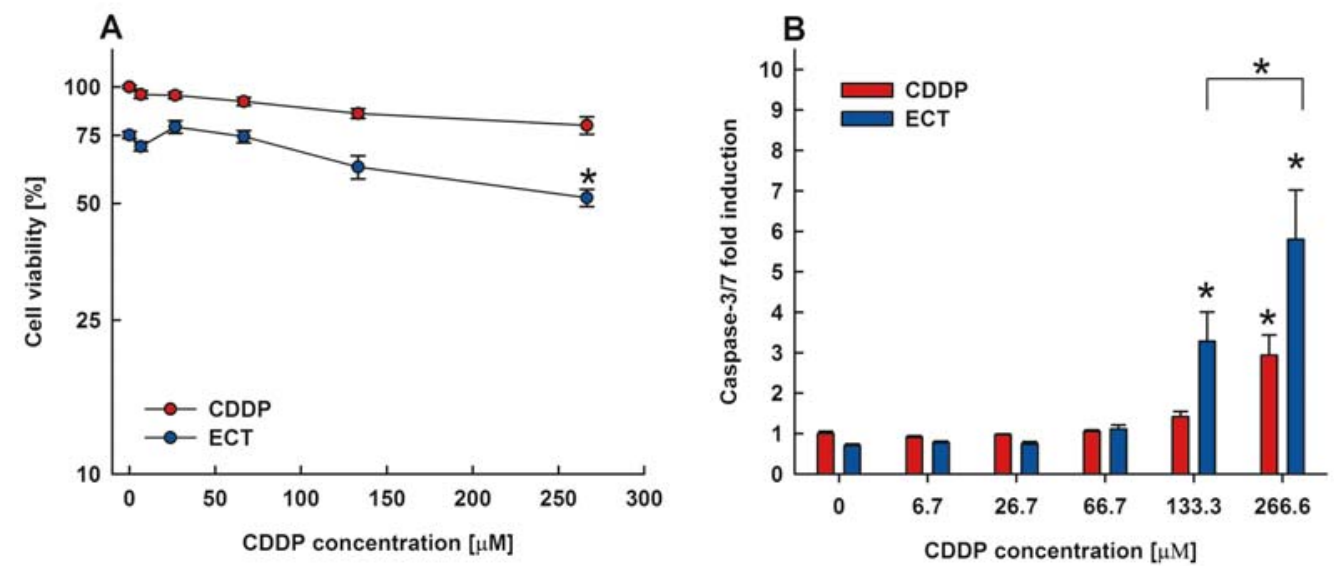

Figure 3. Cell viability (A) and caspase-3/7 fold induction (B) of CMT-93 cells after electrochemotherapy with CDDP. Data are mean values pooled from two or three independent experiments. ${ }^{*} \mathrm{p}<0.05$. 
Table 1. $\mathrm{IC}_{50}$ values of CMT-93 cell line treated with either BLM or CDDP with $(+\mathrm{EP})$ or without (-EP) electroporation

\begin{tabular}{llll}
\hline \multicolumn{3}{c}{ IC50 } \\
\hline drug & $-\mathrm{EP}$ & $+\mathrm{EP}$ & fold increase \\
BLM & $0.1 \mu \mathrm{M}$ & $0.0002 \mu \mathrm{M}$ & 500 \\
CDDP & $192.7 \mu \mathrm{M}$ & $68.3 \mu \mathrm{M}$ & 2.8 \\
\hline
\end{tabular}

typical epithelial morphology. The effect of electric pulses on cell morphology was only minor; some cells were enlarged and only a few cells displayed morphological characteristics typical for apoptotic or necrotic cell death. However, morphological changes progressively increased with increasing BLM or CDDP concentrations and also after electrochemotherapy. After treatment with higher BLM or CDDP concentrations, changes in cell size and shape were observed in comparison to control nontreated cells. Cells were enlarged, some were also multinucleated, and cytoplasm was vacuolarized. Apoptotic bodies, piknosis, karyorrhexis, and karyolysis, were also observed in comparison to control cells indicating necrotic cell death. These changes were more evident at higher concentrations of BLM or CDDP. On the other hand, after electrochemotherapy with BLM or CDDP the above-mentioned morphological changes were already observed at lower BLM or CDDP concentrations (Figure 4).

\section{Discussion}

In this study, we demonstrated the effectiveness of electrochemotherapy with BLM or CDDP on the CMT-93 colorectal carcinoma cell line. The exposure of cells to electric pulses enhanced cytotoxicity of both BLM and CDDP. Reduced cell viability was due to apoptotic and necrotic cell death. Furthermore, electrochemotherapy with BLM was more cytotoxic than electro-
Table 2. The range of $\mathrm{IC}_{50}$ values of different human and murine tumour cell lines treated with either BLM or CDDP with (+EP) or without (-EP) electroporation

\begin{tabular}{lll}
\hline \multicolumn{3}{c}{ IC50 } \\
\hline drug & $-\mathrm{EP}$ & $+\mathrm{EP}$ \\
BLM & $0.1-500 \mu \mathrm{M}$ & $0.0002-4.3 \mu \mathrm{M}$ \\
CDDP & $0.83-1000 \mu \mathrm{M}$ & $0.083-106 \mu \mathrm{M}$ \\
\hline
\end{tabular}

chemotherapy with CDDP in CMT-93 colorectal carcinoma cells.

Our results demonstrate enhanced cytotoxicity of both chemotherapeutic drugs after electrochemotherapy. After exposure of the CMT-93 cell line to a combination of electric pulses and the chemotherapeutic drug, the cells were 2.8-fold more sensitive to CDDP and 500-fold more sensitive to BLM in comparison to exposure to the drug alone. A similar study also tested susceptibility of colorectal carcinoma cell lines Colorectal 26 and MC38 to electrochemotherapy. It demonstrated that these cells were much more sensitive to BLM cytotoxicity. Furthermore, cytotoxicity potentiation was significant only for BLM, but not for CDDP treatment. ${ }^{9}$

Previously, $\mathrm{IC}_{50}$ values (Table 2 ) were determined for different human and murine tumour cell lines for treatment with BLM or CDDP alone or in combination with electroporation. $3,6,9,11-13$ Compared to these studies, CMT-93 cells appear more resistant to CDDP then other cell lines, even after electroporation, although electroporation significantly increased sensitivity to CDDP. CMT-93 cells were more sensitive to BLM, and after electroporation, cytotoxicity was potentiated 500-fold. Our results are also in agreement with the previously reported fact that electroporation of cells potentiates BLM cytotoxicity up to several thousandfold, whereas CDDP cytotoxicity is potentiated up to 80 -fold. ${ }^{14}$

The difference between enhancement of BLM and CDDP cytotoxicity can be as- 


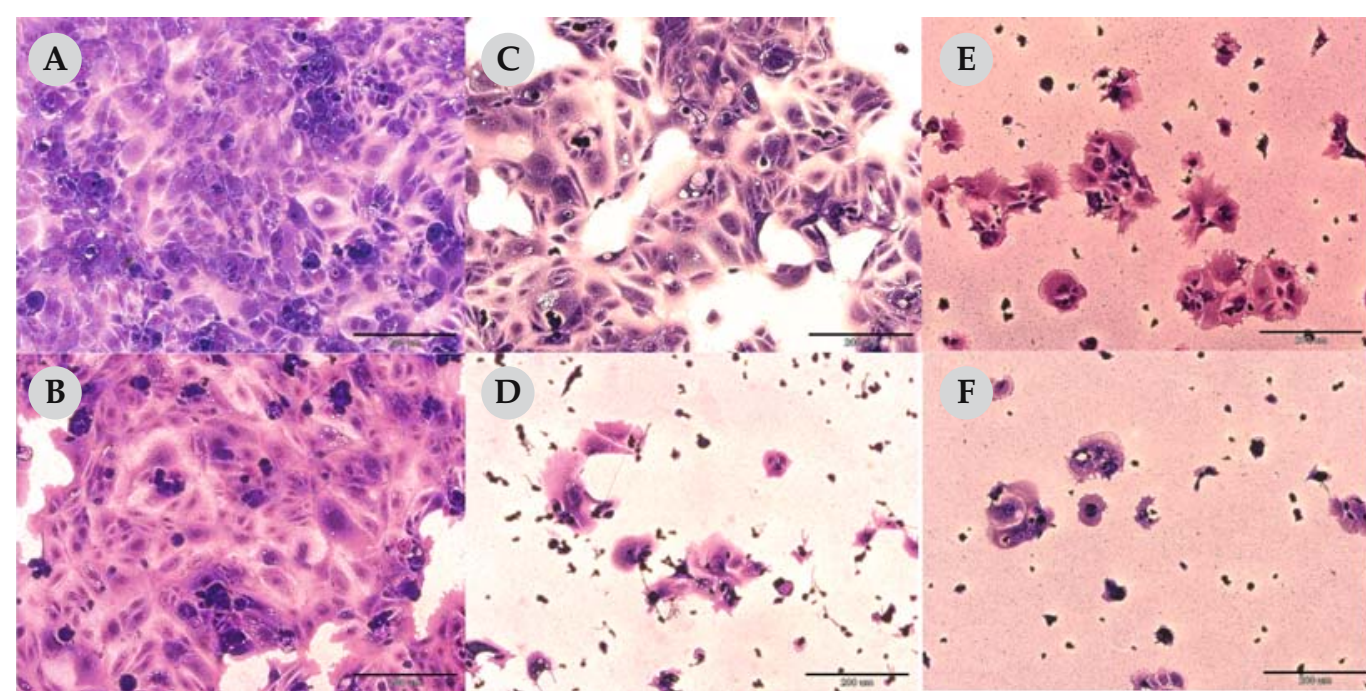

Figure 4. Changes in cell morphology were determined with Giemsa staining. (A) Control non-treated CMT-93 cells. (B) Cells exposed to electric pulses only. (C) Cells exposed to $1 \mu \mathrm{M}$ BLM. (D) Cells exposed to electrochemotherapy with $1 \mu \mathrm{M}$ BLM. (E) Cells exposed to $266.6 \mu \mathrm{M}$ CDDP. (F) Cells exposed to electrochemotherapy with 266.6 $\mu$ M CDDP.

cribed to the uptake of the drugs and also intracellular action of these drugs. Namely, the plasma membrane limits both BLM and CDDP uptake in the cells, as they cannot freely diffuse through the membrane. CDDP is a small inorganic molecule that enters the cells to some extent by passive diffusion and also by active transport via carrier molecules. ${ }^{15,16}$ However, the overall flux across the membrane is limited. On the other hand, BLM is a complex organic molecule, and as such cannot diffuse freely across the plasma membrane. ${ }^{17}$ The exact mechanism of its uptake is not known, however, involvement of receptor proteins on the plasma membrane is indicated. ${ }^{18}$

DNA is the main intracellular target of both BLM and CDDP. However, the mechanism of their cytotoxicity differs. CDDP interacts with DNA to form DNA-protein and DNA-DNA crosslinks. ${ }^{19}$ On the other hand, BLM induces single- and doublestrand DNA breaks..$^{20}$ When DNA damage, induced by either CDDP or BLM, exceeds the threshold level, cell death is triggered. The primary cytotoxic mechanism of DNA- damaging antitumour drugs may be induction of apoptosis. However, other types of cell death can occur in cell cultures exposed to the same drug. Individual cell death after BLM or CDDP exposure might be determined by several factors. It is dependent on drug concentration, the availability of energy and the metabolic condition of the cell. ${ }^{15,21,22}$ BLM-induced DNA damage can trigger the apoptotic, pseudoapoptotic or mitotic cell death pathway. At low BLM concentrations, cells die of mitotic cell death, at intermediate BLM concentrations apoptosis is induced, whereas at high BLM concentrations, an apoptosis-like process takes place. ${ }^{20,23}$ Also, apoptosis, necrosis, and mitotic cell death have been found in the same population of CDDP-treated cells. $^{21,24}$ At high CDDP concentrations $(800 \mu \mathrm{M})$, cells undergo necrotic cell death over a few hours after treatment, whereas at low CDDP concentration $(8 \mu \mathrm{M})$ cells undergo apoptosis following exposure to the drug over several days. ${ }^{22}$

Apoptosis is a mode of cell death characterized by unique morphological and bio- 
chemical features. These include loss of cellcell contact, cell shrinkage and blebbing, recognition by phagocytic cells, condensation and fragmentation of the nucleus, dependence on the energy supplied by ATP, and active protein synthesis. ${ }^{21,25}$ Apoptosis results from activation of the caspase family of aspartate-specific proteases. Upstream caspases are activated early in the apoptotic process and they activate downstream caspases, such as caspase-3 and -7. These caspases are largely responsible for the cleavage of many other cellular proteins, leading to apoptosis. ${ }^{21}$ Measurements of caspase-3 and caspase- 7 activity can be used to detect apoptosis in cell cultures.

Since caspase activation is dependant on metabolic activity of the cell, the cell viability assay and caspase-3/7 activity assay were used to evaluate cell death pathway after electrochemotherapy. Cell viability and caspase-3/7 activity were determined 16 hours after electrochemotherapy, and caspase-3/7 activity was normalized to the number of viable cells. Only cells with an active metabolism can produce ATP and form a caspase activation complex, leading to activation of executioner caspases-3 and -7. Our study demonstrated decreased cell viability after exposure to BLM or CDDP. However, loss of cell viability was more prominent at high concentrations. Cell viability was further decreased after electrochemotherapy. The effect was more pronounced after electrochemotherapy with BLM than CDDP. Furthermore, electrochemotherapy with either BLM or CDDP activated caspases-3 and -7 . However, the caspase- $3 / 7$ fold induction was significantly increased only at the highest concentrations of BLM and CDDP used.

Our results suggest that at low BLM concentrations, cells die after a few cell cycles in a caspase-independent slow cell death process and are in agreement with already demonstrated results that at a BLM concen- tration of $10 \mathrm{nM}$ and below cells die slowly through a mitotic cell death. ${ }^{23}$ Our results further demonstrated that at the highest tested BLM concentrations $(0.1 \mu \mathrm{M}$ and 1 $\mu \mathrm{M})$, caspase- $3 / 7$ activation is apparent and this leads to the conclusion that apoptosis is triggered. The highest concentrations used are too low to induce excessive DNA damage that would lead to rapid cell death. However, DNA damage seems sufficient to activate executioner caspases and apoptosis.

After electrochemotherapy with CDDP, cell viability was significantly reduced at $266.6 \mu \mathrm{M}$ and significant caspase-3/7 fold induction was seen at $133.3 \mu \mathrm{M}$ and $266.6 \mu \mathrm{M}$. This indicates that apoptosis is triggered at these high concentrations. Similarly to BLM, at low CDDP concentrations, cells were metabolically active and caspase-3/7 fold induction was not significantly increased. Also, it was previously demonstrated that at low CDDP concentrations $(8 \mu \mathrm{M})$ cells die of apoptotic death over several days. ${ }^{22}$ In our experiments, caspase-3/7 activity was measured 16 hours after electrochemotherapy, which is too short a time to induce enough DNA damage to induce apoptosis at these low concentrations.

Although caspase-3/7 activation was significant at high concentrations, not all cells underwent apoptosis. Morphological changes observed after treatment with BLM or CDDP or electrochemotherapy with BLM or CDDP were the presence of apoptotic bodies, piknosis, karyorrhexis, and karyolysis. On the one hand, apoptotic bodies, piknosis and karyorrhexis are hallmarks of apoptosis, whereas on the other hand, karyolysis is typical for necrotic cells. Our results demonstrated that cells died of either apoptotic or necrotic cell death after electrochemotherapy with BLM or CDDP. Necrotic cells were more abundant at higher BLM or CDDP concentrations, especially after electrochemotherapy. These results 
are in agreement with cell viability and the caspase-3/7 activity assay. However, reduced cell viability at high BLM or CDDP concentrations after electrochemotherapy was not only due to apoptosis, but also due to necrosis which resulted in pronounced reduction of the cell's clonogenic potential.

To conclude, our study confirmed that CMT-93 colorectal carcinoma cells are sensitive to electrochemotherapy with both BLM and CDDP. To apply electrochemotherapy to the treatment of colorectal carcinoma, special electrodes that allow delivery of electric pulses to more deep-seated tumours must be developed. Currently, electrode systems are under development for intra-luminal delivery by endoscopes, laparoscopic systems or intravascular catheters. ${ }^{26}$ Further development of special electrodes will permit application of electrochemotherapy to the treatment of colorectal carcinoma for those patients that cannot undergo traditional treatment modalities due to severe complications.

\section{Acknowledgements}

The authors would like to thank Dr. Andrej Cör for his advice on cell staining and cell morphology and Dr. Mireille Treeby for proof-reading the manuscript. The authors acknowledge the financial support of the state budget by the Slovenian Research Agency (programme number P3-0003, project number J3-0485).

\section{References}

1. Sersa G, Cemazar M, Miklavcic D, Rudolf Z. Electrochemotherapy of tumours. Radiol Oncol 2006; 40: 163-74.

2. Teissie J, Escoffre JM, Rols MP, Golzio M. Time dependence of electric field effects on cell membranes. A review for a critical selection of pulse duration for therapeutical applications. Radiol Oncol 2008; 42: 196-206.

3. Cemazar M, Sersa G, Miklavcic D. Electrochemotherapy with cisplatin in the treatment of tumour cells resistant to cisplatin. Anticancer Res 1998; 18: 4463-6.

4. Orlowski S, Belehradek J Jr, Paoletti, Mir LM. Transient electropermeabilization of cells in culture. Increase of the cytotoxicity of anticancer drugs. Biochem Pharmacol 1988; 37: 4727-33.

5. Jaroszeski MJ, Dang V, Pottinger C, Hickey J, Gilbert R, Heller R. Toxicity of anticancer agents mediated by electroporation in vitro. Anticancer Drugs 2000; 11: 201-8.

6. Cemazar M, Miklavcic D, Mir LM, Belehradek J Jr, Bonnay M, Fourcault D, et al. Electrochemotherapy of tumours resistant to cisplatin: a study in a murine tumour model. Eur J Cancer 2001; 37: 1166-72.

7. Sersa G. The state-of-the-art of electrochemotherapy before the ESOPE study; advantages and clinical uses. EJC Suppl 2006; 4: 52-9.

8. Marty M, Sersa G, Garbay JR, Gehl J, Collins CG, Snoj M, et al. Electrochemotherapy - An easy, highly effective and safe treatment of cutaneous and subcutaneous metastases: Results of ESOPE (European Standard Operating Procedures of Electrochemotherapy) study. EJC Suppl 2006; 4: 3-13.

9. Kuriyama S, Matsumoto M, Mitoro A, Tsujinoue $\mathrm{H}$, Nakatani T, Fukui H, et al. Electrochemotherapy for colorectal cancer with commonly used chemotherapeutic agents in a mouse model. Dig Dis Sci 2000; 45: 1568-77.

10. Kuriyama S, Tsujinoue H, Toyokawa Y, Mitoro A, Nakatani T, Yoshiji H, et al. A potential approach for electrochemotherapy against colorectal carcinoma using a clinically available alternating current system with bipolar snare in a mouse model. Scand J Gastroenterol 2001; 36: 297-302.

11. Cemazar M, Miklavcic D, Sersa G. Intrinsic sensitivity of tumour cells to bleomycin as an indicator of tumour response to electrochemotherapy. Jpn J Cancer Res 1998; 45: 328-33. 
12. Kranjc S, Cemazar M, Grosel A, Pipan Z, Sersa G. Effect of electroporation on radiosensitization with cisplatin in two cell lines with different chemo- and radiosensitivity. Radiol Oncol 2003; 37: 101-7.

13. Kambe M, Arita D, Kikuchi H, Funato T, Tezuka F, Gamo M, et al. Enhancement of the efficacy of anticancer drugs with electroporation: successful electrochemotherapy against gastric cancer cell lines in vivo and in vitro. Int J Clin Oncol 1997; 2: 111-7.

14. Sersa G, Miklavcic D, Cemazar M, Rudolf Z, Pucihar G, Snoj M. Electrochemotherapy in treatment of tumours. EJSO 2008; 34: 232-40.

15. Fuertes MA, Castilla J, Alonso C, Perez JM. Cisplatin biochemical mechanism of action: from cytotoxicity to induction of cell death through interconnections between apoptotic and necrotic pathways. Curr Med Chem 2003; 10: 257-66.

16. Cepeda V, Fuertes M, Castilla J, Alonso C, Quevedo C, Perez JM. Biochemical mechanisms of cisplatin cytotoxicity. Anticancer Agents Med Chem 2007; 7: 3-18.

17. Tounekti O, Kenani A, Foray N, Orlowski S, Mir LM. The ratio of single- to double-strand DNA breaks and their absolute values determine cell death pathway. Brit J Cancer 2001; 84: 1272-9.

18. Chen J, Stubbe J. Bleomycins: towards better therapeutics. Nat Rev Cancer 2005; 5: 102-12.

19. Siddik ZH. Cisplatin: mode of cytotoxic action and molecular basis of resistance. Oncogene 2003; 22: 7265-79.

20. Tounekti O, Pron G, Belehradek J, Mir LM. Bleomycin, an apoptosis-mimetic drug that induces two types of cell death depending on the number of molecules internalized. Cancer Res 1993; 53: 5462-9.

21. Gonzales VM, Fuertes MA, Alonso C, Perez JM. Is cisplatin-induced cell death always produced by apoptosis? Mol Pharmacol 2001; 59: 657-63.

22. Wang D, Lippard SJ. Cellular processing of platinum anticancer drugs. Nat Rev Drug Discov 2005; 4: 307-20.

23. Mekid H, Tounekti O, Spatz A, Cemazar M, El Kebir FZ, Mir LM. In vivo evolution of tumour cells after the generation of double-strand DNA breaks. Brit J Cancer 2003; 88: 1763-71.

24. Vakifahmetoglu H, Olsson M, Tamm C, Heidari N, Orrenius S, Zhivotovsky B. DNA damage induces two distinct modes of cell death in ovarian carcinomas. Cell Death Differ 2008; 15: 555-66.
25. Taylor RC, Cullen SP, Martin SJ. Apoptosis: controlled demolition at the cellular level. Nat Rev Cancer 2008; 9: 231-41.

26. Sadadcharam M, Soden DM, O'Sullivan GC. Electrochemotherapy: An emerging cancer treatment. Int J Hyperthermia 2008; 24: 263-73. 